\title{
Evaluation of the decision-making process for urban public transport in India: a Delphi approach
}

\author{
Nitin Lambat*, Vijay Kapse and Chandra Sabnani \\ Department of Architecture and Planning, Visvesvaraya National Institute of Technology, Nagpur 440010 , India
}

\begin{abstract}
The Government of India has proposed and constructed various mass rapid transit projects, such as metro rail and bus rapid transit system (BRTS) projects, under the purview of the National Urban Transport Policy (NUTP), Jawaharlal Nehru National Urban Renewal Mission (JnNURM) and other such schemes. However, with less experience in these newly proposed and constructed systems, the projects are surrounded by controversies and doubts. Many questions have been raised regarding the decision-making process for selecting mass rapid transit systems (MRTS) modes. This study attempts to check these doubts and identify other issues associated with the decision-making process. Thus, the study's objective is to identify and prioritize the issues associated with the decision-making process of selecting modes of public transport (MRTS) in India. The study uses the Delphi method and represents a successful application of the approach in urban transport planning. The study identifies 12 issues and their priority in the decision-making process of selecting a public transport (MRTS) mode. The study concludes that the prevailing situations in decision-making process in India contradict the guidelines suggested in NUTP.
\end{abstract}

Keywords: Delphi, India urban transport, MRTS India, public transport, urban transport.

IN Indian cities, lack of effective planning and land-use controls has resulted in widespread sprawled development extending rapidly in all directions, increasing the number and length of trips for most Indians, including those using public transport ${ }^{1-4}$. The unrestricted development has resulted in significant increase in traffic needs, number of vehicles and the accessibility needs of the urbanizing population, in turn putting an enormous burden on the transport infrastructure, especially public transport $^{1-5}$.

The Government of India, with the objective of meeting the transport needs of an urban population, introduced the National level policy in 2006, in the form of the National Urban Transport Policy (NUTP) ${ }^{1}$, and initiated many urban transport projects under the Jawaharlal Nehru

\footnotetext{
*For correspondence. (e-mail: nitin.lambat@gmail.com)
}

National Urban Renewal Mission (JnNURM) and other such schemes. With the introduction of this policy and JnNURM, special attention has been given to public transport, and most cities started planning for their individual needs. Various mass rapid transit projects such as metro rail and bus rapid transit system (BRTS) projects were proposed and developed in most cities, governed by corporations, special purpose vehicles (SPVs) or special consortiums of the state, central and local bodies and private players ${ }^{3}$.

However, with little experience in these newly proposed and constructed systems, the projects have been surrounded by controversies and doubts. Many questions have been raised on the decision-making process for selecting the modes of mass rapid transit systems (MRTS). Experts raised doubts about the images and types of modes and claimed that specific modes of MRTS are preferred in India as a solution to city mobility needs, irrespective of the city's characteristics. Metro rail systems are always given preference in the decision-making process of selecting an MRTS mode ${ }^{6-9}$. Even the city's characteristics and the commuters' needs - trip length, density, urban form, accessibility, travel time, affordability, etc. are overlooked for this reason ${ }^{6-8,10}$. Moreover, these newly constructed MRTS have failed to provide effective and efficient modes of public transport to the urban population. Studies conducted on the proposal and construction of these MRTS found the justifications for the projects invalid, and the systems proved to be failures $^{6,9}$. Thus, Advani and Tiwari ${ }^{6}$ conclude, 'It is not necessary that a planned high capacity system will generate high demand and thus these systems need careful analysis while planning'. Goel and Tiwari ${ }^{8}$ state that, according to the 12th Five-Year Plan for urban transport produced by the Planning Commission, Indian cities with population more than 2 million should start planning for rail-based public transport systems, and those with population more than 3 million may start constructing systems. It is necessary to analyse the statement of the planning commission, as it is improper to plan MRTS based on the criterion of population alone. The choice of MRTS is affected by many city and commuter characteristics such as trip length, urban form, coverage, walkable distance and mode interchange. Studies suggest that light rail transit system (LRTS) and surface rail might be more efficient and economic modes of public transport in 
India ${ }^{11,12}$. However, these modes are overlooked in the decision-making process, and metro rail and BRTS are given preference. NUTP ${ }^{1,13}$ suggested promoting all the proven technologies and states that the MRTS mode should be selected based on the city characteristics and needs. However, the prevailing situation appears to contradict these suggestions of $\mathrm{NUTP}^{9,12}$. According to Sreenivas $^{9}$, the detailed project report (DPR) for the Pune metro rail project shows many weaknesses, overestimates and flaws in the process. Stating observations, he shows that the process seems to be ad hoc and without scientific basis. The process does not include public participation and does not appear to be sufficiently transparent. Further, these systems are not planned appropriately and are not allocated on an equitable basis. These systems are also more capital intensive. With respect to the Delhi Metro, Randhawa ${ }^{10}$ claimed that the metro rail project is causing gentrification in the city, restructuring the urban space for capital accumulation by dispossessions of the poor, giving priority to the middle class and converting the city into a 'world class city', without providing a mass rapid transit solution on an equitable basis. Similarly, a study of the Ahmedabad BRTS shows that, even though the BRTS is promoted as a low-cost alternative of MRTS, it is not successful in doing so ${ }^{14}$. The cost of the Ahmedabad BRTS is considerably higher than bus services and shared auto fares in Ahmedabad and is not affordable for low-income people. The system is not successful in providing access to most of the urban poor, especially women.

Among these issues, the development and performance of MRTS in Indian cities leaves many questions unanswered. To ensure the efficient and effective performance of MRTS in Indian cities, it is first necessary to understand the problems associated with the decision-making process. Thus, this study aims to identify these problems and any other issues associated with the decision-making process and determine whether the guidelines provided in NUTP are currently followed or disregarded in the decision-making process in India.

The Delphi method is used in this study with two major objectives. The first objective is to identify and prioritize the issues associated with the decision-making process of selecting the mode of the public transport system (MRTS) in India. The second objective is to identify and prioritize the necessary indicators for the comparative evaluation of the selection of the MRTS mode. This paper presents the results and findings of the first objective.

The Delphi technique/method is a structured communication process among a group of experts, with controlled opinion feedback. The method is a valid research technique that is widely used in various disciplines of academic and professional fields. The Delphi method can be used for identifying and prioritizing issues, forecasting and decision-making, formulating policies, etc. This study identifies and prioritizes the issues associated with the decision-making process of selecting an MRTS mode.
This is a complex issue with very little empirical information available, requiring knowledge from experts in urban and transport planning. The Delphi method is flexible in its design, having a strong statistical basis and vast practical applications in various fields. This method does not require a large sample size and in-person meetings with the experts. Thus, the Delphi method is used in this study. This study represents a successful application of the Delphi method in urban transport planning. This study identifies 12 issues and their priority in the decision-making process of selecting a mode of public transport (MRTS). The study concludes that the prevailing situations in decision-making process for selecting a mode of public transport in India contradict the guidelines suggested in NUTP.

\section{Delphi method: an approach to issue identification}

The Delphi method was designed and developed by the RAND Corporation in the 1950 s, while they were conducting a series of studies for the U.S. Army for bomb strategy development, and the method was first proposed for non-military use $\mathrm{e}^{15-22}$. The main objective of this study is to obtain the most reliable consensus among a group of experts by conducting several rounds of questionnaires and controlled opinion feedback ${ }^{15,17,22,23}$.

Okoli and Pawlowski ${ }^{17}$ cited the work of Linstone and Turoff $^{24}$ to capture common characteristics of Delphi as 'a method for structuring a group communication process so that the process is effective in allowing a group of individuals, as a whole, to deal with a complex problem. Accomplishing this 'structured communication' is provided as there is: some feedback of individual contributions of information and knowledge; some assessment of the group judgement or view; some opportunity for individuals to revise views; and some degree of anonymity for the individual responses'. Paré et al. ${ }^{25}$ explained Delphi as the structural process of collecting distilled knowledge from a panel of experts by means of a questionnaire combined with controlled opinion feedback. Further Paré et $a l .{ }^{25}$ discussed Delphi as "The process is viewed as a series of rounds, and in each round, participants communicate their opinions through a questionnaire that is returned to the researchers, who collect, edit, and return to every participant, a statement of the position of the panel and the participant's own position.' This method enables researchers to observe how experts discuss a complex problem through a structured communication process, as well as collate divergent responses into a convergent overview $^{26}$.

The Delphi technique may be used for forecasting and decision-making when there is a lack of available information. It is used when judgement is indispensable and involves the use of experts' knowledge when little or no empirical evidence exists ${ }^{15,17,23,25,27}$. The Delphi technique is commonly used for forecasting and decision-making 
based on experts' opinions. The Delphi method is used as a research tool in various fields such as information systems, physical and social sciences, engineering, education, business and economics, public administration and medical sciences ${ }^{15,25}$ and is a widely and exclusively used research tool in information systems ${ }^{17,19,23,25,27}$.

The most important benefit of the Delphi is, it maintains anonymity and avoids direct confrontation of the experts ${ }^{17,25}$. Regarding this, Okoli and Pawlowski ${ }^{17}$ stated that 'The controlled interaction appears to be more conducive to independent thought on the part of the experts and aid them in the gradual formation of a considered opinion. Direct confrontation, on the contrary, all too often induces the hasty formulation of preconceived notions, an inclination to close one's mind to novel ideas, a tendency to defend a stand once taken, or, alternatively and sometimes alternately, a predisposition to be swayed by persuasively stated opinions of others.'

Delphi studies can be majorly classified into four types - classical Delphi, decision Delphi, policy Delphi and ranking type Delphi - and these types are generally classified based on their objectives and approaches ${ }^{17,23,25}$. Among these four types, ranking type Delphi is the most extensively used. The main objective of the ranking type Delphi is to identify and prioritize key factors, items, or other types of issues ${ }^{17,19,23,25}$. As the main objective of this study is to identify and prioritize the issues related to the selection process for MRTS modes, the ranking type Delphi approach was adopted.

\section{Research methodology}

This study adopts the ranking type Delphi approach. The methodological approach suggested by Kobus and Westner $^{23}$, is followed in this study. This methodology consists of four phases, as represented in Figure 1. Phase 1, selecting the right experts for the study, is based on Okoli and Pawlowski ${ }^{17}$, while phases 2 to 4 for data collection, analysis and representation are based on the guidelines of Schmidt ${ }^{19}$ and Paré et al. ${ }^{25}$.

\section{Choosing the right experts}

The results of the Delphi method are dependent on the opinions, valuable inputs and judgements of the experts. Thus, choosing the right and qualified experts is the most critical stage in the Delphi method ${ }^{17,23,25,27}$. Okoli and Pawlowski ${ }^{17}$ stated that choosing the experts is 'perhaps the most important yet most neglected part' and thus suggested useful guidelines on how to select the right experts for conducting a rigorous Delphi study. It is of utmost importance to select experts who have extensive knowledge and experience in the respective topic. Moreover, as a Delphi study depends on experts' knowledge and opinions, the study does not represent any population, and thus the sample size should not be dependent on any statistical or probability approach ${ }^{17,22,26}$. There is no typical sample size in the Delphi method ${ }^{23,28}$. According to $\mathrm{Ju}$ and $\mathrm{Jin}^{27}$ and Alyami et al. ${ }^{26}$, the optimum number of experts in a Delphi study varies between 10 and 50, while Kobus and Westner ${ }^{23}$ identify various panel sizes of less than 7 , between 10 and 15 , or approximately 30 , suggested in the literature. Okoli and Powlowski ${ }^{17}$ suggest four panels, each composed of 10 to 18 experts. In this study, this phase is handled with attention, and efforts are made to follow the guidelines suggested by Okoli and Pawlowski ${ }^{23,25,27}$. Efforts are also made to maintain a sample size of at least 50 .

In this study, the experts were identified based on their publications and work backgrounds. This study identifies experts with academic, private and government backgrounds. The fundamental approach was to select experts working in research, planning, social, or technical positions and who have backgrounds in urban transport. An extensive list of experts was obtained from Urban Mass Transit Company (UMTC). The list includes the names of officials and persons from all backgrounds of urban transport and those who were invited to and attended various workshops and training programmes in urban transport planning conducted by UMTC in association with the Institute of Urban Transport (IUT), India and the Ministry of Urban Development (MoUD). Additionally, names were identified from published papers, books and various academic institutes in the urban transport discipline in various Indian cities. Finally, with the help of identified names from the above lists, experts were screened using their designation and work backgrounds, and a consolidated list of experts was prepared. An invitation was then sent in the initial round to all the identified experts on this consolidated list, and they were asked to forward this to other urban transport experts in their vicinity.

\section{Data collection}

A questionnaire was designed with the objective of researching the selection process for the modes of public transport (MRTS) in Indian cities, and experts were asked to state their opinions regarding the selection process. The data was collected using the online survey portal www.surveymonkey.com. A letter stating the objective of study and a survey link were sent via e-mail. The experts were also asked and encouraged to participate in the study through personal conversations. Moreover, in round 1, an in-depth individual interview was conducted with experienced and well-known experts in the urban transport field, and their opinions were noted.

As suggested by $\mathrm{Schmidt}^{19}$, the initial round could be conducted as a brainstorming session followed by a narrowing down phase $\mathrm{e}^{17,25,26,29}$. In this study, a combined brainstorming and narrowing down phase was conducted with a broad literature review and explorative individual expert interviews in different cities in India. 


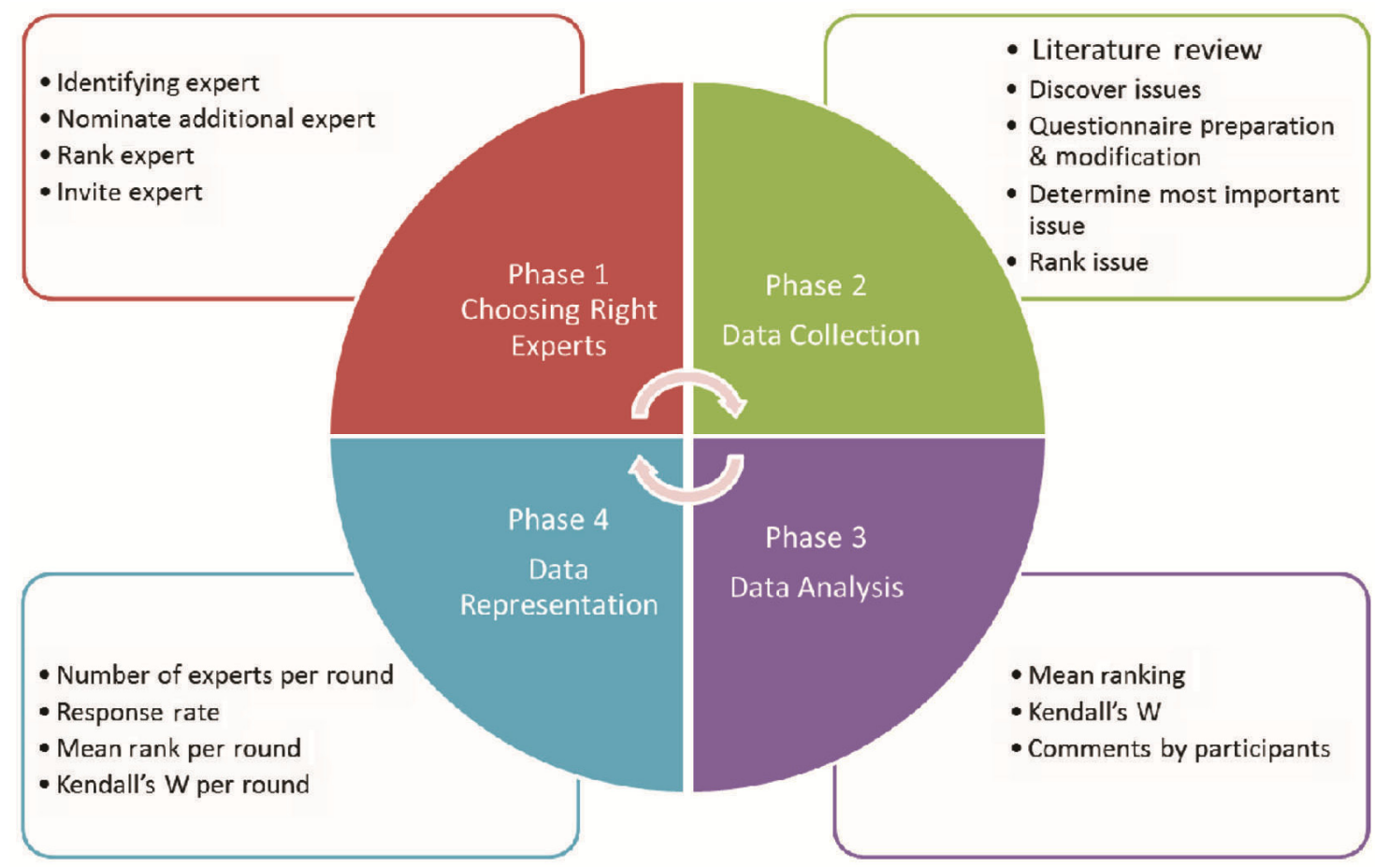

Figure 1. Methodology approach of Delphi study.

Table 1. Experts response rate for Delphi study

\begin{tabular}{lccc}
\hline Delphi rounds & $\begin{array}{c}\text { Experts } \\
\text { invited }\end{array}$ & $\begin{array}{c}\text { Experts } \\
\text { participated }\end{array}$ & $\begin{array}{c}\text { Response } \\
\text { rate (\%) }\end{array}$ \\
\hline 1 & unknown & 104 & - \\
2 & 150 & 84 & 56 \\
3 & 84 & 70 & 83 \\
4 & 70 & 64 & 91 \\
\hline
\end{tabular}

Round 1 was conducted as a brainstorming and narrowing down stage, and the next rounds were considered iterative rounds. Thus, this study consisted of four rounds of survey questionnaires, including three rounds of iterations. Table 1 shows the number of experts who were invited and who participated, and the response rates in the respective rounds of the study. In round 1 , more than 125 responses were received; however, after the screening, only 104 responses were considered valid. In the subsequent rounds, the experts were screened based on experience. The responses of the experts having more than five years of experience were considered in the subsequent iterative rounds. The names of additional experts, identified from the earlier responses from the experts, were then added to this consolidated list. In round 2 , the experts important for the study but unable to participate in round 1 were selected and invited for the next Delphi rounds. In the later rounds, the experts were invited based on their participation in the preceding rounds.

In the brainstorming phase of the Delphi method, issues or indicators may be identified based on the litera- ture. In this study, the issues associated with the decisionmaking process for selecting MRTS modes were identified based on the literature. The literature suggested that in the decision-making process, metro rail systems were given preference while LRTS and suburban rail systems were overlooked. Some researchers have suggested that BRTS was also given preference. Moreover, important factors such as socioeconomic aspects and city characteristics were not considered and, in some cases, selection is based solely on population and is without any scientific basis. The study reports and feasibility studies conducted for mode selection also showed ad hoc processes and many flaws.

In the initial round, the experts' opinions were collected using the online questionnaire and personal interviews. The experts were asked to state their opinions on the current basis of selection of MRTS modes in India. The data collected in round 1 suggest that the decisionmaking process was based on various criteria, either individually or in combination. Most experts suggested that the selection of MRTS mode was based on city characteristics, trip length, urban form, topography, travel patterns and characteristics, demand, peak hour peak demand traffic (PHPDT) and so on, which were further categorized into aspect of city characteristics. Some of the experts highlighted socio-economic aspects, including affordability, fare, comfort, connectivity and travel time, and some cited feasibility studies, population, and preference for metro rail. The above aspects were already discussed in the literature and were considered the major aspects in the decision-making process. In addition to these aspects, 
Table 2. Results of Kendall's coefficient of concordance in Delphi study-identified issues and rankings

\begin{tabular}{|c|c|c|c|c|c|c|c|}
\hline \multirow{2}{*}{$\begin{array}{l}\text { Statements } \\
\text { ('The proposal and selection of a } \\
\text { new mode of MRTS in Indian cities is...') }\end{array}$} & \multicolumn{2}{|c|}{ Round 4} & \multicolumn{2}{|c|}{ Round 3} & \multicolumn{2}{|c|}{ Round 2} & \multirow{2}{*}{$\begin{array}{c}\text { Round } 2 \\
\text { Initial } \\
\text { positions }\end{array}$} \\
\hline & $\begin{array}{c}\text { Rank } \\
\text { (mean rank) }\end{array}$ & Mean & $\begin{array}{c}\text { Rank } \\
\text { (mean rank) }\end{array}$ & Mean & $\begin{array}{c}\text { Rank } \\
\text { (mean rank) }\end{array}$ & Mean & \\
\hline Influenced by political will & $1(9.38)$ & 5.94 & $2(8.33)$ & 5.54 & $1(8.55)$ & 5.55 & 2 \\
\hline Higher preference is given to metro rail & $2(8.60)$ & 5.70 & $1(8.48)$ & 5.66 & $2(8.22)$ & 5.39 & 9 \\
\hline Light rail transit systems are neglected & $3(7.93)$ & 5.28 & $3(7.89)$ & 5.2 & $6(6.73)$ & 4.77 & 11 \\
\hline Suburban rail systems are neglected & $4(7.77)$ & 5.34 & $4(7.69)$ & 5.27 & $5(6.95)$ & 5.01 & 12 \\
\hline Based on population size & $5(7.27)$ & 4.86 & $5(7.64)$ & 5.04 & $4(7.15)$ & 4.93 & 4 \\
\hline $\begin{array}{l}\text { Done with respect to feasibility studies } \\
\text { (financial and technical) }\end{array}$ & $6(7.06)$ & 4.72 & $6(6.86)$ & 4.64 & $3(7.39)$ & 4.96 & 3 \\
\hline Based on 4-stage modelling & $7(5.95)$ & 4.33 & $8(6.07)$ & 4.43 & $7(6.65)$ & 4.73 & 1 \\
\hline Based on socioeconomic benefits & $8(5.77)$ & 4.31 & $9(5.57)$ & 4.23 & $9(5.90)$ & 4.46 & 5 \\
\hline Done with respect to city characteristics & $9(5.72)$ & 4.3 & $7(6.59)$ & 4.56 & $8(6.19)$ & 4.54 & 6 \\
\hline $\begin{array}{l}\text { Dependent on alternative analysis/ } \\
\text { comparative evaluation }\end{array}$ & $10(4.67)$ & 3.84 & $10(4.81)$ & 3.86 & $10(5.04)$ & 4.04 & 8 \\
\hline Based on commuters' opinions & $11(4.05)$ & 3.39 & $11(4.42)$ & 3.77 & $11(4.73)$ & 3.98 & 7 \\
\hline \multirow[t]{2}{*}{ Higher preference is given to bus rapid transit } & $12(3.83)$ & 3.41 & $12(3.66)$ & 3.33 & $12(4.51)$ & 3.83 & 10 \\
\hline & \multicolumn{2}{|c|}{ Kendall's, $W=0.274$} & \multicolumn{2}{|c|}{ Kendall's, $W=0.219$} & \multicolumn{2}{|c|}{ Kendall's, $W=0.144$} & \\
\hline
\end{tabular}

the experts also mentioned commuters' opinions, political influence, the 4-stage model study and alternative analysis. However, alternative analysis was cited by very few experts, indicating less awareness of that aspect and limited application in the field.

Based on the opinions collected in round 1 and the issues identified in the literature, the issues were classified into 12 major categories. Further, these aspects were formulated into 12 statements to complete the sentence 'The proposal and selection of a new mode of MRTS in Indian cities is' (e.g. the proposal and selection of a new mode of MRTS in Indian cities is done with respect to city characteristics). These 12 statements are listed in Table 2.

The questionnaire for round 2 was designed using the sentence with 12 statements. The experts were asked to share their agreement on a 7-point Likert scale with 1 as 'strongly disagree', 2 as 'disagree', 3 as 'somewhat disagree', 4 as 'neutral', 5 as 'somewhat agree', 6 as 'agree' and 7 as 'strongly agree'. The process was then repeated according to the Delphi technique procedure, with the modified questionnaire based on the ranking of the statements according to the analysis in the respective iterations, and then stopped when the topping criterion was satisfied.

As the experts' anonymity is one of the fundamental characteristics of Delphi, the experts' anonymity was assured and maintained throughout the process.

\section{Data analysis}

Achieving the most reliable consensus is the main objective in a Delphi study. Hence, it is important to understand when to stop the iteration process and conclude the study. However, there is disagreement among researchers about the degree of consensus and the appropriate statis- tical methodology to apply ${ }^{15,18,21,27}$. Von der Gracht ${ }^{21}$, in a review study, concluded that 'general standards on how to measure consensus in a Delphi study do not yet exist'. Most studies suggest that researchers have used both parametric and non-parametric statistical techniques to indicate consensus ${ }^{15,20,21,27,30}$. However, a few studies suggest that, because ranking type Delphi studies use ordinal data, it is a questionable practice to use the mean and standard deviation for a normal frequency distribution to represent a valid interpretation ${ }^{21,27}$. Ju and $\mathrm{Jin}^{27}$ state that most studies employ a qualitative approach to report consensus; a few of those provide statistical analysis based on means, medians, standard deviations or simply a percentage of the distribution, but very few have addressed the huge gap that exists with using the nonparametric technique to analyse this critical issue. Further, $\mathrm{Ju}$ and $\mathrm{Jin}^{27}$ emphasized that different researchers have used different statistical elements to represent the boundaries, and the boundaries between high and adequate agreement are also vague. On the other hand, Von der Gracht ${ }^{21}$ studied many works on Delphi and cautioned understanding the difference between consensus and stability of experts' opinions. He advised that it is not desirable to use only consensus to conclude the study; instead, there must be a thorough consideration of the data for stability of experts' opinions. To ensure the validity and rigour of a Delphi study, analysis using the nonparametric statistics is advised $^{21,27}$. Therefore, in this study, nonparametric statistical methods are preferred to verify consensus and later it is preferred to check the stability of the experts' opinions.

Kendall's coefficient of concordance, $W$, as suggested by Schmidt, is widely recognized as the best nonparametric statistical method for measuring consensus in ranking type Delphi studies ${ }^{17,22,23,25}$. Schmidt ${ }^{19}$ designed excellent guidelines for measuring consensus and applying the stopping rule to stop the iteration process. He suggested 
that there are two statistical criteria to determine when to stop the process. The first criterion is strong consensus and the second is no significant difference in the mean rankings for successive rounds in case strong consensus is not achieved ${ }^{19}$. Paré et al. ${ }^{25}$ suggest that the stopping rule can be applied when one of three stopping criteria is satisfied: (1) $W>0.7$, indicating a strong level of consensus; (2) three rounds have been performed; (3) the mean rankings for two successive rounds are not significantly different, based on the McNemar test. Kobus and Westner stated that the 'stopping criteria for the Delphi data collection are either strong consensus or a clear indication that no more difference in answers can be expected'. For calculating consensus, the value of $W$ ranges from 0 to 1 , with 0 indicting no consensus and 1 representing perfect consensus. Schmidt also provided a table interpreting the different values of $W$.

Kendall's coefficient of concordance, $W$, is used as the main measure of consensus in this study. However, after three iterations, strong consensus was not achieved among the group of experts. Thus, the stability of the experts' answers was then examined ${ }^{17,19,21,23,25}$ to maintain the validity of the study and to prevent experts from dropping out, overburdening the experts with additional rounds and potentially developing artificial consensus in the process ${ }^{19,21,25}$. Therefore, according to the stopping criteria suggested in previous studies, McNemar's test and the Wilcoxon matched pair signed-rank test were conducted to examine the differences in the experts' opinions between successive rounds. Further, the data from the respective rounds were analysed using the intraclass correlation coefficient test to assess the consistency of the responses in consecutive rounds. The rankings of the issues in the respective rounds are mostly unchanging, signifying the stability of the experts' opinions.

\section{Data representation}

A distinctive characteristic of the Delphi method is the important stage of presenting the analysed data to the experts, enabling them to review the data and rethink their opinions. The results for each round were also shared with the experts. The values of Kendall's coefficient of concordance, $W$, were represented, along with the mean ranks and mean values in each round, to identify the central tendencies. The experts were informed that they may change their opinions based on the results of previous rounds. The details regarding the experts' participation in the respective rounds were also shared with the experts.

\section{Results and discussion}

The main criterion for stopping the iteration process is strong consensus. However, in cases of weak consensus, it is necessary to conduct at least three iterations, and there must be stability in the experts' opinions in the suc- cessive rounds. In this study, Kendall's coefficient of concordance, $W$, is used to measure consensus, with values of $W>0.7$ representing strong consensus. The results obtained for the Kendall's coefficients of concordance and the priorities of the statements are illustrated in Table 2. In this study, the Kendall's coefficients of concordance, $W$, calculated using SPSS 20.0, were 0.144; 0.219 and 0.274 respectively, in successive iterations. These results indicate very weak agreement among the experts, but with some improvement in the values of $W$ in the successive rounds. However, this study conducts three iterations and thus satisfies one of the stopping criteria. Later, to check the stability of the experts' opinions in successive rounds, this study conducted a McNemar test, a Wilcoxon matched pair signed-rank test and an intra-class correlation coefficient test using SPSS 20. The values obtained for the levels of significance in McNemar's test and the Wilcoxon matched pair signed-rank test are within the satisfactory levels of significance for all 12 statements in the successive rounds, confirming that there is no significant change in the experts' opinions. Further, the intraclass correlation coefficient test found satisfactory levels of reliability and consistency in the experts' rankings for the statements in successive iterations. To interpret the level of consistency, this study follows the guidelines of Cicchetti $^{31}$ and Blackman and Koval ${ }^{32}$. The guidelines suggest that reliability coefficient values of less than 0.4 represent poor consistency, values between 0.4 and 0.59 represent fair consistency, values between 0.6 and 0.74 indicate good consistency and values of more than 0.75 represent excellent consistency. The results of the intraclass correlation coefficient test are shown in Table 2, which demonstrate that the overall agreement and stability over the successive rounds was satisfactory. The level of consistency for 5 of the statements was excellent and varied from good to fair for the remaining statements. Thus, the stopping criteria for this Delphi study was satisfied, and the results of this study were valid.

The results show that the statement influenced by political will' ranked at the top. The mean value of 5.94 suggests that the experts agreed that it is one of the critical issues in the decision-making process for the selection of MRTS mode. However, the level of significance for the statement in the successive rounds was poor. This result may be because, in the initial round, very few experts mentioned influence of political will. In the successive rounds, when this statement was added, the experts started accepting this fact and commented freely on this issue. The consistency between rounds 3 and 4 was poor compared to that between rounds 2 and 3 . Additionally, the mean value in round 4 was higher than those in rounds 2 and 3, indicating a shift in the experts' opinions. These results show that, as the process progressed, hesitation among the experts reduced, helping to build their confidence in the later Delphi rounds. The same can be highlighted from the experts' comments 
Table 3. Results of intra-class correlation coefficient test in Delphi study

\begin{tabular}{|c|c|c|c|c|}
\hline $\begin{array}{l}\text { Statements } \\
\text { ('The proposal and selection of a new mode of MRTS in Indian cities is...') }\end{array}$ & $\begin{array}{l}\text { Consistency for } \\
\text { rounds } 2 \text { and } 3\end{array}$ & $\begin{array}{l}\text { Consistency for } \\
\text { rounds } 3 \text { and } 4\end{array}$ & $\begin{array}{l}\text { Average } \\
\text { measure }\end{array}$ & $\begin{array}{l}\text { Level of } \\
\text { consistency }\end{array}$ \\
\hline Influenced by political will & 0.372 & 0.053 & 0.380 & Poor \\
\hline Higher preference is given to metro rail & 0.281 & 0.468 & 0.616 & Good \\
\hline Light rail transit systems are neglected & 0.321 & 0.616 & 0.660 & Good \\
\hline Suburban rail systems are neglected & 0.256 & 0.445 & 0.577 & Fair \\
\hline Based on population size & 0.466 & 0.410 & 0.648 & Good \\
\hline Done with respect to feasibility studies (financial and technical) & 0.572 & 0.675 & 0.820 & Excellent \\
\hline Based on 4-stage modelling & 0.567 & 0.553 & 0.788 & Excellent \\
\hline Based on socioeconomic benefits & 0.527 & 0.614 & 0.786 & Excellent \\
\hline Done with respect to city characteristics & 0.565 & 0.523 & 0.740 & Good \\
\hline Dependent on alternative analysis/comparative evaluation & 0.549 & 0.651 & 0.781 & Excellent \\
\hline Based on commuters' opinions & 0.462 & 0.581 & 0.790 & Excellent \\
\hline Higher preference is given to bus rapid transit & 0.373 & 0.542 & 0.633 & Good \\
\hline
\end{tabular}

regarding the influence of political will in the decisionmaking process. Some experts stated that the choice of the mode was based on political preferences rather than an understanding of the technical feasibility and viability of designing a public transportation system. In the opinions of some experts, the decision was made primarily by the political class, and all cities want metro rail systems without much of a deliberative process. There is a perception that a metro is the only symbol of development. The experts' comments indicated that, in the decision-making process under the purview of political will, important criteria and studies were neglected, showing an inclination towards metro rail systems. The results also show that preference for metro rail systems was one of the critical issues affecting decision-making, ranking 2nd, with a mean ranking of 8.60 . The statements regarding the neglect of LRT and suburban rail systems in the decisionmaking process were ranked 3rd and 4th respectively. The mean values for these statements show that experts agree that these aspects are major issues. The influence of political will and preference for metro rail are probable reasons that decision makers neglect LRT and suburban rail systems. An expert stated that 'the proposal frequently starts with the question: can we build a metro in this city? And the answer depends on whether there are $30 \mathrm{~m}$ wide roads!' Further, population size is an important issue in the decision-making process of selecting an MRTS. The literature discusses that, according to the guidelines in the 12th five-year plan, the selection of MRTS should be based on population. However, no scientific data support this guideline.

Further, the criteria feasibility study, 4-stage modelling, socioeconomic benefits and city characteristics were successively ranked with the agreement of experts from neutral to somewhat agree. This result shows that these important criteria for selection of the MRTS mode were not given much attention in the decision-making process. However, the experts' comments suggest that the MRTS mode must be selected based on the specific characteristics of mode, commuters need and city characteristics.
There must be a comprehensive mobility plan, and the studies must incorporate the opinions of the commuters and consider socio-economic aspects. However, these criteria are currently overlooked and considered less important. An expert claimed, 'Cities nowadays are choosing fancier systems like metro rail, without any due diligence and evaluation on whether the city is ready for such a capital intensive system in such a volatile atmosphere. Yes, cities are conducting detailed studies, preparing DPRs, spending resources (time and money), but those are just mere eyewash to the public and made to suit and meet the financial viability of the project.'

Regarding the issue of higher preference to BRTS, the experts did not agree with the statement, and it was ranked last with a mean rank of 3.83. This result suggests that BRTS did not get preference in the decision-making process and therefore was not considered an issue. However, some experts commented that BRTS has a negative image in most cities, which needs to be corrected.

It is surprising that comparative evaluation/alternative analysis and commuters' opinions - arguably the most important issues in the decision-making process-are ranked 10th and 11th, with mean values of 3.84 and 3.39 respectively. The mean values for both statements indicate that the experts' agreement is neutral to somewhat disagree on these issues. Thus, both issues were either neglected or given very little attention in the decisionmaking process. The Ministry of Housing and Urban Affairs (MoHUA) has made it mandatory to submit an alternative analysis under the Metro Rail Policy 2017 (ref. 33) introduced in August 2017. According to this policy, it is necessary to incorporate alternative analysis into the project report when seeking central government assistance over the horizon of 30 years. A comparative analysis is also mandatory under the metro rail policy, indicating the preference for metro rail in India. The appraisal guidelines released by MoHUA in September 2017 discuss Cost Benefit Analysis (CBA); however, $\mathrm{CBA}$ has some limitations with respect to qualitative criteria, and thus other alternative analysis methods may 
be considered into the policy guidelines ${ }^{34}$. The main objective of NUTP is to plan for people rather than for vehicles, and to promote a more equitable allocation of road space to people. NUTP advises that the choice of the MRTS mode should depend on the characteristics of the city. The Government should encourage planners to consider all the proven technologies and not promote any specific technology. However, the results of this study indicate the opposite conclusion.

\section{Conclusion}

This study uses the Delphi method to identify issues and their priority in the decision-making process of selecting a Public Transport (MRTS) mode in India. The results represent a valid and successful application of the Delphi method in urban transport planning. This study identifies 12 issues and their priority in the decision-making process of selecting a public transport (MRTS) mode in India. However, the experts disagree on the 12th issue regarding preference for BRTS, thus eliminating it as an issue in the decision-making process. It is concluded that the influence of political will, higher preference for metro rail, and disregard of LRT and suburban rail systems are the major problems in the decision-making process of selecting an MTRS mode in India. This study confirms that population is also a criterion in mode selection; the literature cites the guidelines of the 12th Five-Year Plan and advises proper scientific study. The study also concludes that the important criteria of city characteristics, socioeconomic benefits and feasibility studies are given less attention. The feasibility studies and the 4-stage modelling study are either manipulated or not considered seriously. The study strongly infers that the important criteria of comparative evaluation and commuters' opinions, which reflect the core objectives of NUTP, are very insignificantly considered in the decision-making process of selecting a public transport mode. In conclusion, 'the prevailing situations in decision-making process for selecting the mode of public transport in India profoundly contradict the guidelines suggested in NUTP'.

1. Ministry of Urban Development G, National Urban Transport Policy, 2006; http://urbanindia.nic.in/policies/TransportPolicy.pdf

2. Agarwal, O. P., Urban transport. In India Infrastructure Report 2006 - Urban Infrastructure, New Delhi, Oxford University Press, 2006, pp. 106-129; http://www.idfc.com/pdf/report/IIR-2006.pdf

3. Agarwal, O. P. et al., Review of urban transport in India, New Delhi, IUT \& CSTEP, UNEP Riso Centre on Energy, Climate and Sustainable Development Technical University of Denmak, 2014; https://wedocs.unep/bitstream/handle/20.500.11822/16958/CaseStudy MetroRails.pdf? sequence $=1$ \&isAllowed $=\mathrm{y}$

4. Pucher, J., Korattyswaroopam, N. and Ittyerah, N., The crisis of public transport in India: overwhelming needs but limited resources. J. Publ. Transp., 2004, 7(3), 1-20.

5. Singh, S. K., Urban transport in India: issues, challenges, and the way forward. Eur. Transp., 2012, 52(52), 1-26.
6. Advani, M. and Tiwari, G., Evaluation of public transport systems: case study of Delhi Metro. In START-2005, IIT Kharagpur, Kharagpur, India, 2005, pp. 1-8; http://tripp.iitd.ernet. in/publications/paper/planning/mukti_metro_kharagpur_05.pdf

7. Mohan, D., Mythologies, metro rail systems and future urban transport. Econ. Polit. Wkly., 2008, 43, 41-53; http://tripp.iitd. ernet.in/delhibrts/metro/Metro/Metro Mythology08.pdf

8. Goel, R. and Tiwari, G., Promoting low carbon transport in india: Case Study of Metro Rails in Indian Cities, 2014; http://www. indiaenvironmentportal.org.in/files/file/Review\%20of\%20Urban\%20Transport $\% 20 \mathrm{in} \% 20$ India.pdf

9. Sreenivas, A., Urban transport planning: lessons from the proposed Pune metro rail. Econ. Polit. Wkly, 2011; xlvi(6), 27-32; http://www.epw.in/commentary/urban-transport-planning-lessonsproposed-pune-metro-rail.html

10. Randhawa, P., Delhi metro rail beyond mass transit. Econ. Polit. Wkly, 2012, XLVII, 25-29.

11. Sanghvi, D. and Varia, H. R., Light rail transit-today's need for developing cities in India. Int. J. Sci. Res., 2015, 4(3), 596601.

12. Ravibabu, M. and Sree, V. P., Public transport for Indian urban agglomerations - a strong case for surface rail. Econ. Polit. Wkly, 2014, 49(23), 105-116.

13. Ministry of Urban Development G, National Urban Transport Policy, 2014; www.iutindia.org

14. Mahadevia, D., Joshi, R. B. and Datey, A., Ahmedabad's BRT system: a sustainable urban transport panacea? Econ. Polit. Wkly, 2013, xlviiI(48), 56-64; http://www.researchgate.net/publication/ 259289231

15. Landeta, J., Current validity of the Delphi method in social sciences. Technol. Forecast. Soc. Change, 2006, 73(5), 467-482; doi:10.1016/j.techfore.2005.09.002.

16. Masser, I. and Foley, P., Delphi revisited: expert opinion in urban analysis. Urban Stud., 1987, 24(3), 217-225; doi:10.1080/ 00420988720080351.

17. Okoli, C. and Pawlowski, S. D., The Delphi method as a research ool: an example, design considerations and applications. Inform. Manage., 2004, 42(1), 15-29; doi:10.1016/j.im.2003.11.002.

18. Rowe, G. and Wright, G., The Delphi technique as a forecasting tool: issues and analysis. Int. J. Forecast., 1999, 15(4), 353-375; doi:10.1016/S0169-2070(99)00018-7.

19. Schmidt, R. C., Managing Delphi surveys using nonparametric statistical techniques. Decision Sci., 1997, 28(3), 763-774; doi:10.1111/j.1540-5915.1997.tb01330.x.

20. Shah, H. A. and Kalaian, S. A., Which is the best parametric statistical method for analyzing Delphi data? J. Mod. Appl. Stat. Meth., 2009, 8(1), 226-232; doi:10.22237/jmasm/1241137140.

21. Von der Gracht, H. A., Consensus measurement in Delphi studies. review and implications for future quality assurance. Technol. Forecast. Soc. Change, 2012, 79(8), 1525-1536; doi:10.1016/ j.techfore.2012.04.013.

22. Habibi, A., Sarafrazi, A. and Izadyar, S., Delphi technique theoretical framework in qualitative research. Int. J. Eng. Sci., 2014, 3(4), 8-13; doi:10.1016/S0169-2070(99)00018-7.

23. Kobus, J. and Westner, M., Ranking-type delphi studies in IS research : step-by-step guide and analytical extension. IADIS Int. Conf. Inf. Syst., 2016, 28-38.

24. Linstone, H. A. and Turoff, M., The Delphi Method-Techniques and Applications, 1975; ISBN 0-201-04294-0.

25. Paré, G., Cameron, A. F., Poba-Nzaou, P. and Templier, M., A systematic assessment of rigor in information systems rankingtype Delphi studies. Inform. Manage., 2013, 50(5), 207-217; doi:10.1016/j.im.2013.03.003.

26. Alyami, S. H., Rezgui, Y. and Kwan, A., Developing sustainable building assessment scheme for Saudi Arabia: Delphi consultation approach. Renew. Sustain. Energ. Rev., 2013, 27, 43-54; doi: 10.1016/j.rser.2013.06.011. 
27. $\mathrm{Ju}, \mathrm{B}$. and $\mathrm{Jin}, \mathrm{T}$., Incorporating nonparametric statistics into Delphi studies in library and information science. Inform. Res., 2015, 18(03), 1-11.

28. Hasson, F., Keeney, S. and McKenna, H., Research guidelines for the Delphi survey technique. J. Adv. Nurs., 2000, 32(4), 10081015; doi:10.1046/j.1365-2648.2000.t01-1-01567.x.

29. Wassenaar, A., van den Boogaard, M., Schoonhoven, L. and Pickkers, P., Determination of the feasibility of a multicomponent intervention program to prevent delirium in the intensive care unit: a modified RAND Delphi study. Aust. Crit. Care, 2016, doi:10.1016/j.aucc.2016.12.004.

30. Yang, Y.-N., Methodology for testing the stability of experts' opinions between successive rounds of Delphi studies. In Conference Proceedings, American Educational Research Association, Chicago, IL, 2003, pp. 1-8.

31. Cicchetti, D. V., Guidlines, criteria, and rules of thumb for evalauting normed and standardized assessment instruments in psychology. Psychol. Assess., 1994, 6(4), 284-290; doi:10.1037/ 1040-3590.6.4.284.

32. Blackman, N. J. M. and Koval, J. J., Interval estimation for Cohen's kappa as a measure of agreement. Stat. Med., 2000,
19(5), 723-741; doi:10.1002/(SICI)1097-0258(20000315)19:5<

723::AID-SIM379>3.0.CO;2-A.

33. Ministry of Housing and Urban Affairs G, Metro Rail Policy, 2017.

34. Ministry of Housing and Urban Affairs G, Appraisal Guidelines for Metro Rail Project Proposals Ministry of Housing and Urban Affairs Government of India, 2017.

ACKNOWLEDGEMENTS. We thank all the experts for their contribution and continuous support in Delphi study. We acknowledge Visvesvaraya National Institute of Technology, Nagpur for facilities.

Received 9 May 2018; revised accepted 7 February 2019

doi: $10.18520 / \mathrm{cs} / \mathrm{v} 116 / \mathrm{i} 10 / 1706-1714$ 